\title{
Vaginal trichomoniasis
}

\author{
Monica Cenkowski BSc, Beverly Wudel MD, Vanessa Poliquin MD MSc
}

Cite as: CMAJ 2022 February 14;194:E217. doi: 10.1503/cmaj.211088

\section{Trichomoniasis is the most common curable sexually \\ 1 transmitted infection worldwide}

Although trichomoniasis is not a reportable disease, the estimated North American prevalence is $2.8 \%-3.1 \%$ among women and $0.2 \%-0.5 \%$ among men, with higher rates in patients with multiple sexual partners..$^{1,2}$ Infection with Trichomonas vaginalis increases the risk of HIV acquisition and puts a pregnant person at a $40 \%-50 \%$ increased risk of poor outcomes, including premature rupture of membranes and preterm birth. ${ }^{3}$

\section{2}

\section{Routine screening for trichomoniasis is performed only in}

HIV-positive women; otherwise, test only if symptomatic Symptoms include purulent vaginal discharge, pruritis, dysuria and dyspareunia. ${ }^{1}$ Although wet mount microscopy (sensitivity 51\%-65\%), antigen detection (sensitivity $82 \%-95 \%$ ) and nucleic acid hybridization (sensitivity $63 \%$ ) assays are available, nucleic acid amplification testing is the most sensitive assay for detecting $T$. vaginalis in women. ${ }^{3}$ Testing for men is not universally available in Canada and men are typically treated empirically.

\section{3}

\section{First-line treatment for pregnant and nonpregnant patients is metronidazole}

Treatment with either $2 \mathrm{~g}$ orally once or $500 \mathrm{mg}$ orally twice daily for 7 days is $82 \%-88 \%$ effective, with limited evidence suggesting that the 7 -day regimen is superior. ${ }^{4}$ Cure rates are highest, increasing to $95 \%$, when a partner is also treated. ${ }^{4}$

\section{4}

Sexual partners must be treated at the same time as the patient upon diagnosis of trichomoniasis

Concurrent treatment of sexual partners is often overlooked by clinicians and is a common reason for reinfection. ${ }^{1}$

\section{If $T$. vaginalis vaginitis persists, the possibility of \\ ( metronidazole resistance should be considered}

As many as 1 in 10 cases of $T$. vaginalis may be resistant to metronidazole. ${ }^{5}$ Persistent positive testing of a patient or their partner should prompt consideration for referral to Infectious Diseases or a sexually transmitted infections clinic, which may send a sample for culture and susceptibility testing at the United States Centers for Disease Control and Prevention. If resistance to metronidazole is confirmed, experts may request access to alternative therapies (e.g., tinidazole) through Health Canada.

\section{References}

1. Kissinger P. Trichomonas vaginalis: a review of epidemiologic, clinical and treatment issues. [Internet]. BMC Infect Dis 2015;15:307.

2. Gratrix J, Plitt S, Turnbull L, et al. Trichomonas vaginalis prevalence and correlates in women and men attending ST clinics in Western Canada. Sex Transm Dis 2017;44:627-9.

3. Meites E, Gaydos CA, Hobbs MM, et al. A review of evidencebased care of symptomatic Trichomoniasis and asymptomatic Trichomonas vaginalis infections. Clin Infect Dis 2015;61(Suppl 8):S837-48.

4. Section 4-9: Canadian guidelines on sexually transmitted infections - management and treatment of specific syndromes - vaginal discharge. Ottawa: Public Health Agency of Canada; 2013. Available: https://www.canada. ca/en/public-health/services/infectious-diseases/sexual -health-sexually-transmitted-infections/canadian-guidelines/ sexually-transmitted-infections/canadian-guidelines -sexually-transmitted-infections-26.html (accessed 2021 Jan. 3)

5. Kirkcaldy RD, Augostini P, Asbel LE, et al. Trichomonas vaginalis antimicrobial drug resistance in 6 US cities, STD Surveillance Network, 2009-2010. Emerg Infect Dis 2012; 18:939-43.

Competing interests: Vanessa Poliquin reports receiving consulting fees from GSK and SearchLight Pharma, and an honorarium from Sanofi Pasteur. No other competing interests were declared.

This article has been peer reviewed.

Affiliations: Max Rady College of Medicine (Cenkowski), University of Manitoba, Winnipeg, Man.; Division of Infectious Diseases, Department of Medicine (Wudel), University of Saskatchewan, Saskatoon, Sask.; Department of Obstetrics, Gynecology and Reproductive Sciences (Poliquin), Max Rady College of Medicine, Winnipeg, Man.

Content licence: This is an Open Access article distributed in accordance with the terms of the Creative Commons Attribution (CC BY-NC-ND 4.0) licence, which permits use, distribution and reproduction in any medium, provided that the original publication is properly cited, the use is noncommercial (i.e., research or educational use), and no modifications or adaptations are made. See: https:// creativecommons.org/licenses/by-nc-nd/4.0/

Correspondence to: Monica Cenkowski, cenkowsm@myumanitoba.ca 